Ambiente \& Água - An Interdisciplinary Journal of Applied Science
ISSN 1980-993X - doi:10.4136/1980-993X
www.ambi-agua.net
E-mail: ambi-agua@agro.unitau.br

\title{
Uso de imagens do LISS-3/Resourcesat-1 e do OLI/Landsat-8 no estudo espacial da queda do nível de água no lago de Furnas no ano de 2012
}

\author{
doi: 10.4136/ambi-agua.1430
}

Received: 17 Jun. 2014; Accepted: 16 Sep. 2014

\author{
Gabriel Thomé Brochado $^{1^{*}}$; Lucrêncio Silvestre Macarringue ${ }^{2}$ \\ ${ }^{1}$ Instituto Nacional de Pesquisas Espaciais (INPE), São José dos Campos, SP, Brasil \\ Departamento de Sensoriamento Remoto \\ ${ }^{2}$ Instituto de Formação em Administração de Terras e Cartografia (INFATEC), \\ Cidade da Matola, província de Maputo, Moçambique \\ Departamento de Investigação e Extensão \\ *Autor correspondente: e-mail: gabrow@ gmail.com, \\ lusimac@gmail.com
}

\section{RESUMO}

O presente trabalho teve como objetivo analisar, por meio de imagens de diferentes sensores e técnicas de geoprocessamento, o efeito da queda do nível de água que ocorreu no Lago de Furnas no ano de 2012. Esta análise foi feita com base nas imagens satélites em três distintos anos: antes do evento (imagens de 2010), durante o evento (imagens de 2012) e depois do evento (imagens do ano de 2013). Para realizar o mapeamento do nível de água nos anos de 2010 e 2012 foram utilizadas imagens do LISS3/Resourcesat-1 e para o ano de 2013 imagens do OLI/Landsat-8, todas processadas e interpretadas em ambiente SIG. O produto final apresenta quatro classes: i) superfície de água permanente nos três anos, ii) superfície seca permanente nos três anos, iii) superfícies de água recuperada e iv) não recuperada até ao último ano (2013). A metodologia consistiu de cinco etapas: preparo, fatiamento, álgebra de mapas, edição matricial e cálculo de áreas. O mapa da redução do nível de água do Lago foi gerado a partir de uma operação matricial algébrica entre as máscaras de superfície de água extraídas das bandas do infravermelho próximo, cujo resultado foi editado manualmente para corrigir erros de classificação. Para validar o mapa foram usadas fotografias veiculadas pela imprensa local, durante o evento de redução de nível de água. Os resultados desta pesquisa permitiram concluir que esta metodologia é fácil de ser reproduzida e pode ser utilizada em outras regiões.

Palavras-chave: imagens orbitais, interpretação de imagens, processamento, reservatório de Furnas.

\section{Spatial study using LISS-3/Resourcesat-1 and OLI/Landsat-8 images to characterize the water level drop in Furnas Lake during 2012}

\begin{abstract}
This study used satellite images and GIS techniques to analyze the effect of the decrease in water level in Furnas Lake during 2012. The analysis was based on satellite images captured during three different periods: prior to the event (images of 2010), during the year of the event (images of 2012) and after the event (images of the year 2013).
\end{abstract}


LISS3/Resourcesat-1 images were used for the years 2010 and 2012 and OLI/Landsat-8 images for the year 2013. The images were processed and interpreted into a GIS environment. The final product had four classes: i) permanent water surface during the three periods, ii) permanent dry surface during the three periods, iii) recovered water surfaces and iv) not recovered until the last period (2013). The methodology consisted of five stages: preparation, density slice, map algebra, raster editing and area calculation. The map of the water level drop in the Furnas Lake was generated by an algebraic matrix operation between the surface water mask drawn based on the near-infrared bands. The result of this operation was manually edited in order to correct classification errors. For data validating, we compared photographs published by local media during the event with the generated maps. The results showed that this methodology is straightforward and easily reproduced and can be used to assess other regions.

Keywords: Furnas reservoir, image processing and interpretation, orbital images.

\section{INTRODUÇÃO}

O Lago de Furnas situa-se na região sul do Estado de Minas Gerais e é o maior reservatório de água do estado, sendo por isso conhecido como Mar de Minas. O lago foi criado em 1963 para servir de represa para a hidrelétrica de Furnas e desde então muitas atividades econômicas têm sido desenvolvidas na região, principalmente relacionadas ao turismo e à pesca (Com chuvas de verão..., 2013). Com a criação do lago, trinta e quatro (34) municípios tiveram parte de seus territórios inundados com o represamento das águas.

Estes municípios, a fim de explorar turisticamente as transformações advindas da criação da represa, buscando a sustentabilidade econômica e a preservação ambiental dos municípios banhados pelo lago, formaram a Associação dos Municípios do Lago de Furnas (ALAGO).

No ano de 2012, o lago sofreu uma grande queda no seu nível de água, chegando a ficar até 13 metros abaixo do seu nível normal (Silva 2012). A redução da lâmina de água no lago foi ocasionada devido à necessidade da hidrelétrica de gerar energia elétrica e, para tal, foram abastecidos outros reservatórios a jusante da barragem. Segundo a empresa Furnas, a geração de energia elétrica é a prioridade, sendo, portanto, um procedimento normal manter as hidrelétricas em funcionamento o ano inteiro (Com chuvas de verão..., 2013). As estimativas para a recuperação do nível de água normal da represa indicavam 3 ou 4 anos, fato que ameaçava a estabilidade da economia local, baseada principalmente em atividades ligadas ao turismo, à agricultura e à pesca. Todavia, os efeitos da queda foram atenuados devido às grandes chuvas que ocorreram no final do ano de 2012 e início de 2013 nas cabeceiras dos rios que alimentam a represa (Com chuvas de verão..., 2013).

Vários estudos que focam nas questões de preservação e conservação de recursos hídricos, ocupação e monitoramento de áreas inundáveis, dinâmicas dos reservatórios de recursos hídricos usando geotecnologias e imagens orbitais têm sido amplamente difundidos (Pinto-Coelho et al., 1994; Butzke, 1995; Mota, 1995; Câmara et al., 1996; Tundisi, 1999). À luz desses estudos, neste trabalho se propõe analisar qualitativamente, por meio de imagens de diferentes sensores orbitais, os efeitos da queda de nível de água na represa e quantificar a área impactada e recuperada por município abrangido.

\section{MATERIAL E MÉTODO}

\section{1. Área de estudo}

O Lago de Furnas é a maior extensão de água do estado de Minas Gerais, ocupando uma área de $1.440 \mathrm{~km}^{2}$. O lago é formado por dois "braços", um a leste e outro a sul da barragem. Do lado leste o principal rio que desagua no lago é o Rio Grande. Do lado sul a represa é 
formada da junção dos rios Verde, Sapucaí, Machado, além de muitos ribeirões e córregos (Figura1) (IPT, 2008).

\section{LAGO DE FURNAS (Minas Gerais)}

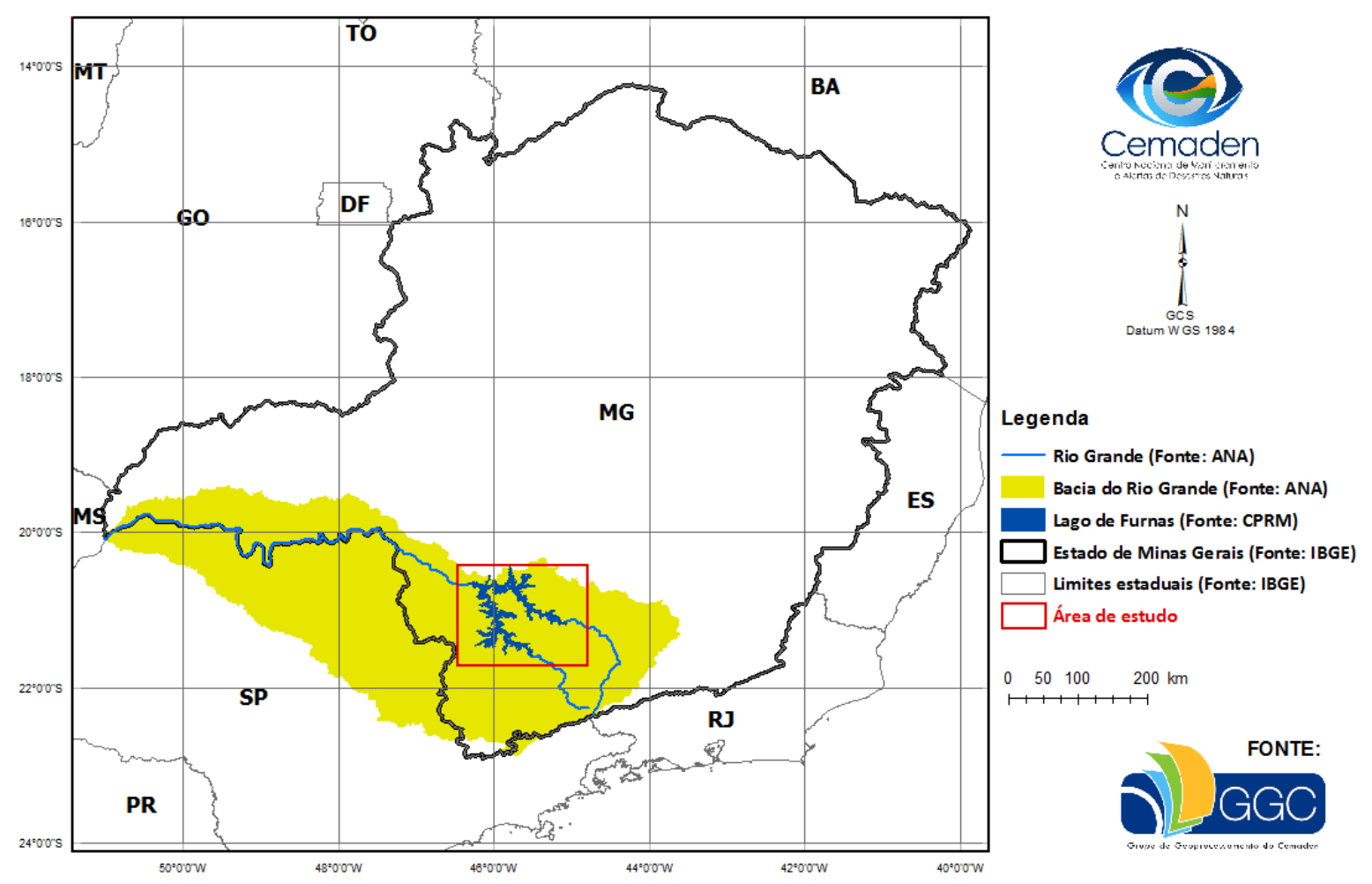

Figura 1. Localização geográfica do lago de furnas na região Sul/Sudoeste do estado de Minas Gerais.

Fonte: Cemaden (2014).

O nível de armazenamento do lago é de 768 metros acima do nível do mar, com o nível máximo de 769,3 metros e o nível mínimo de operação de 750 metros. Ao longo de sua extensão, o lago exibe diversas paisagens com contornos sinuosos, por causa do "mar de morros" sobre o qual a represa foi formada. Na região de Capitólio, existem os cânions do Lago de Furnas, que possuem cerca de 20 metros de altura com várias cachoeiras e reentrâncias, formando uma bela paisagem.

A região insere-se num contexto paisagístico de transição entre a Mata Atlântica e o Cerrado, no entanto, a cobertura vegetal nativa é representada pela Floresta Estacional Semidecídua, constituída por fragmentos de diversos tamanhos e formas que se apresentam como um mosaico heterogêneo (Nascimento et al., 1999 apud Ferreira et al., 2008, Santos et al., 2011). As unidades geomorfológicas mais expressivas da região são caracterizadas por colinas de topo aplainado, com rampas expressivas e os solos predominantes são os Latossolos, com ocorrência de Podzólicos, Litólicos e Cambissolos. O relevo é, em grande parte, constituído por rochas cristalinas (Camargo et al., 1962, apud CAMPOS e SILVA, 1998).

\subsection{Material}

Foram utilizados três conjuntos de imagens para compor os anos, conforme apresentado na Tabela 1. 
Tabela 1. Imagens orbitais utilizadas na composição dos anos.

\begin{tabular}{ccccc}
\hline Ano & Plataforma & Sensor & Órbita/Ponto & Data \\
\hline $\mathbf{2 0 1 0}$ & - & - & $331 / 092$ & $05 / 08 / 2010$ \\
- & - & - & - & - \\
- & - & - & $331 / 093$ & $24 / 08 / 2010$ \\
- & Resourcesat-1 & LISS-3 & $332 / 093$ & $24 / 08 / 2010$ \\
$\mathbf{2 0 1 2}$ & - & - & $331 / 092$ & $17 / 11 / 2012$ \\
- & - & - & $331 / 093$ & $17 / 11 / 2012$ \\
- & - & - & $332 / 093$ & $22 / 11 / 2012$ \\
$\mathbf{2 0 1 3}$ & Landsat-8 & OLI & $219 / 074$ & $12 / 05 / 2013$ \\
- & - & - & $219 / 075$ & $12 / 05 / 2013$ \\
\hline
\end{tabular}

Estas datas foram as que apresentaram melhores imagens (fraca cobertura de nuvens) para este estudo, assume-se que a relativa diferença entre as datas das imagens de 2010 e 2012 pode afetar os resultados desta pesquisa.

A utilização do LISS-3 foi devido ao fato do TM-Landsat 5 estar inoperacional parte do período em análise, que veio a ser substituído pelo Landsat 8, e por outro lado existem aproximações entre as faixas espectrais e resoluções espacial e temporal destes sensores além do fato do OLI ser novo e apresentar relativas vantagens que os anteriores sensores da mesma série que podem ser exploradas tais como maior número de bandas e ortoretificação.

O sensor LISS-3 (Linear Imaging Self Scanning Sensor), um dos 3 sensores a bordo do ResourceSat-1, opera em três faixas espectrais: visível, infravermelho próximo (NIR) e infravermelho de ondas curtas ou médio (SWIR) (NRSA, 2003; Chander, 2013). As especificações técnicas deste sensor são apresentadas na Tabela 2.

Tabela 2. Características das imagens do LISS-3 do satélite ResourceSat-1.

\begin{tabular}{llccccc}
\hline \multicolumn{1}{c}{ Sensor } & Bandas Espectrais & $\begin{array}{c}\text { Resolução } \\
\text { Espectral }\end{array}$ & $\begin{array}{c}\text { Resolução } \\
\text { Espacial }\end{array}$ & $\begin{array}{c}\text { Resolução } \\
\text { Temporal }\end{array}$ & $\begin{array}{c}\text { Área } \\
\text { Imageada }\end{array}$ & $\begin{array}{c}\text { Resolução } \\
\text { Radiométrica }\end{array}$ \\
\hline & Verde & $0.52-0.59 \mu \mathrm{m}$ & & & & \\
$\begin{array}{l}\text { LISS III } \\
\text { (Linear Imaging }\end{array}$ & Vermelho & $0.62-0.68 \mu \mathrm{m}$ & & & & \\
$\begin{array}{l}\text { Self-Scanner) } \\
\text { Satélite IRS-P6 } \\
\text { (Resourcesat-1) }\end{array}$ & $\begin{array}{l}\text { Infravermelho } \\
\text { próximo }\end{array}$ & $0.77-0.86 \mu \mathrm{m}$ & $23,5 \mathrm{~m}$ & 24 dias & $141 \mathrm{~km}$ & 7 bits \\
& $\begin{array}{l}\text { Infravermelho } \\
\text { médio }\end{array}$ & $1.55-1.70 \mu \mathrm{m}$ & & & & \\
& & & & & \\
\hline
\end{tabular}

Fonte: INPE (2013).

Os sensores OLI (Operational Land Imager) e TIRS (Thermal Infrared Sensor) do Landsat 8 operam em 11 bandas espectrais. As imagens obtidas por estes sensores apresentam três resoluções espaciais distintas, conforme mostrado na Tabela 3. São imagens quase prontas, contendo correções geométricas (USGS, 2012a; 2012b) e ambos sensores podem ser usadas de forma compensatória ou complementar (Johnson, 2008). Para este estudo, foram utilizadas as bandas 4, 5 e 6 e 8 (OLI). 
Tabela 3. Características das imagens do OLI e TIRS do satélite Landsat 8.

\begin{tabular}{ccccc}
\hline Banda & Sensor & Faixa espectral $(\mu \mathbf{m})$ & Significado & $\begin{array}{c}\text { Resolução } \\
\text { Espacial (m x m) }\end{array}$ \\
\hline Banda 1 & - & $0,43-0,45$ & Aerossol, costeira* & 30 \\
Banda 2 & - & $0,45-0,51$ & Azul & 30 \\
Banda 3 & - & $0,53-0,59$ & Verde & 30 \\
Banda 4 & - & $0,64-0,67$ & Vermelho & 30 \\
Banda 5 & OLI & $0,85-0,88$ & IV Próximo & 30 \\
Banda 6 & - & $1,57-1,65$ & SWIR 1 & 30 \\
Banda 7 & - & $2,11-2,29$ & SWIR 2 & 30 \\
Banda 8 & - & $0,50-0,68$ & Pancromático & 15 \\
Banda 9 & - & $1,36-1,38$ & Cirrus & 30 \\
Banda 10 & TIRS & $10,60-11,19$ & - & 100 \\
Banda 11 & - & $11,50-12,51$ & - & 100 \\
\hline
\end{tabular}

"utilizada para estudo de aerossol e ambiente costeiro; ${ }^{* *}$ estudar as nuvens cirrus.

Fonte: USGS (2012a; 2012b).

Foi utilizada também a base cadastral dos municípios brasileiros na escala 1:250.000 e o cadastro das localidades do ano de 2010 (IBGE, 2010).

Todos os procedimentos computacionais foram realizados nos aplicativos Envi $4.7 \mathrm{e}$ Spring 4.3.3, e o programa FME 2013 foi usado para o cálculo das informações dispostas na Tabela 4 de impacto/recuperação.

\subsection{Método}

A análise do efeito da queda do nível de água no lago de Furnas e o quanto foi recuperado no ano seguinte foi baseada em uma situação estável do ano de 2010, tomada como referência. A partir do cruzamento do mapa base (ano de 2010) com os mapas do ano de ocorrência do evento (2012) e do ano seguinte (2013) foi possível gerar uma nova informação, relativa à diferença nos níveis de água nos três momentos e quantificar esta diferença para cada município limítrofe do lago.

O mapa base foi obtido através da delimitação do perímetro da lâmina de água no mosaico de imagens na banda do infravermelho próximo, tendo em vista que a água absorve praticamente toda energia radiante nesta região do espectro eletromagnético em contraste com os demais alvos no entorno do lago (Jensen, 2009). Tanto o mapa base, quanto os demais foram gerados a partir de uma operação matricial algébrica, denominada 'fatiamento'. Os erros de delimitação do perímetro da água que surgiram durante a extração semiautomática foram eliminados por meio da edição matricial manual.

No mapa final, foram definidas quatro classes: superfície de água permanente nos três anos, superfície seca permanente nos três anos e superfícies de água recuperada e não recuperada até a data das imagens no ano de 2013. A partir do mapa final, obtido a partir do cruzamento dos três mapas nas três datas (Figura 2), foi gerada uma tabela para quantificar a área que foi impactada e recuperada em cada município banhado pelas águas livres do lago.

A metodologia desenvolvida continha cinco etapas: preparo das imagens, fatiamento, álgebra de mapa, edição matricial e cálculo de área (Figura 2). 


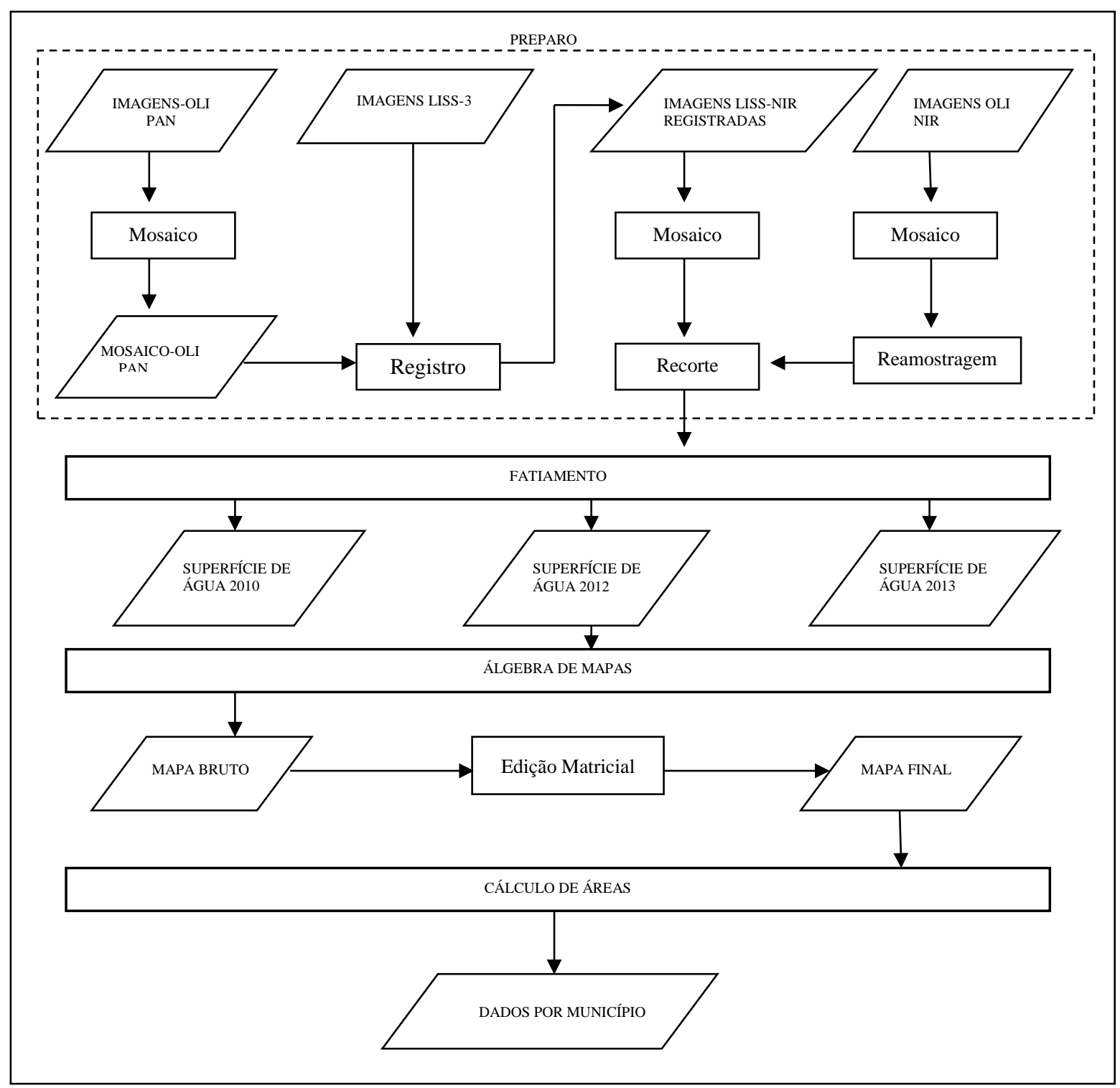

Figura 2. Fluxograma do método.

\subsubsection{Preparo do material}

O preparo consistiu em uma série de operações (Figura 2) necessárias para que a extração da superfície de água livre observável nas imagens pudesse ser realizada através de um programa computacional.

Como a região do lago de Furnas abrange duas cenas do Landsat, órbita/ponto 219/74 e 75 , foi necessário realizar um mosaico dessas duas cenas para obter uma área contínua de todo lago de Furnas. O mosaico, feito com as imagens pancromáticas (banda 8) deste sensor, foi utilizado para o registro das imagens LISS-3/Resourcesat-1. Ao final desta operação as imagens da região do infravermelho próximo de ambos os sensores foram reamostradas para 15 metros e gerado um mosaico para cada ano. Estes mosaicos foram recortados para uma área cujos limites distam cerca de 300 metros do limite da superfície de água livre no ano de 2010 (Figura 3). Esta operação foi realizada com intuito de facilitar os processos subsequentes. 


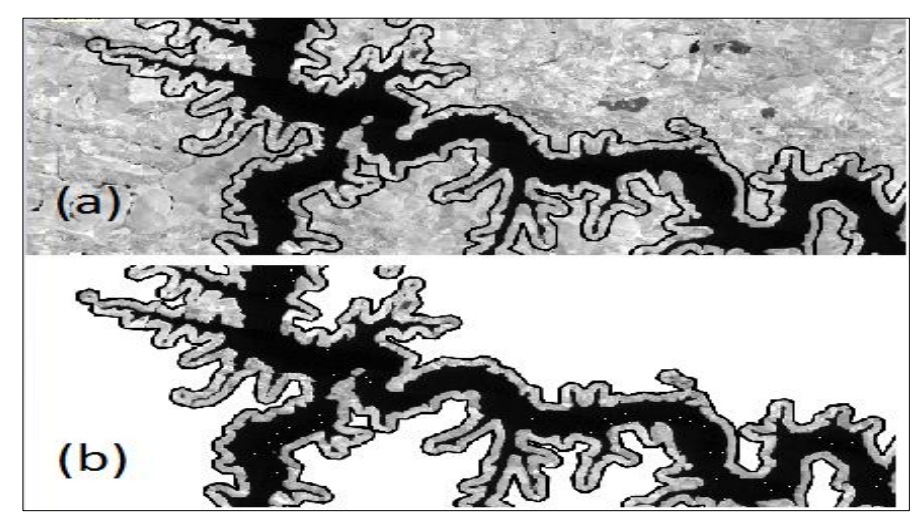

Figura 3. Recorte das imagens. (a) Mosaico das imagens de 2010 com o vetor da área do buffer de $300 \mathrm{~m}$. (b) Resultado do recorte, eliminando o restante da imagem.

\subsubsection{Fatiamento}

A superfície de água livre foi extraída dos mosaicos de cada ano utilizando um procedimento semi-automático, denominado fatiamento. É determinado, para cada ano, um valor de nível de cinza, abaixo do qual os pixels foram classificados como "água" e acima do qual como "seco". Este valor é encontrado empiricamente a partir da análise do histograma do mosaico de cada ano e da inspeção visual do intérprete.

A Figura 4 apresenta os histogramas dos mosaicos, em que pode ser observada a presença de dois "picos", um relativo à resposta espectral da água e outro da região seca. Portanto, o limiar ótimo de separabilidade entre água e solo está no vale de máxima inflexão dos histogramas. Os valores dos limiares encontrados para os anos 2010, 2012 e 2013 foram respectivamente 35,55 e 35 . A Figura 5 apresenta o resultado do fatiamento para o ano de 2010.
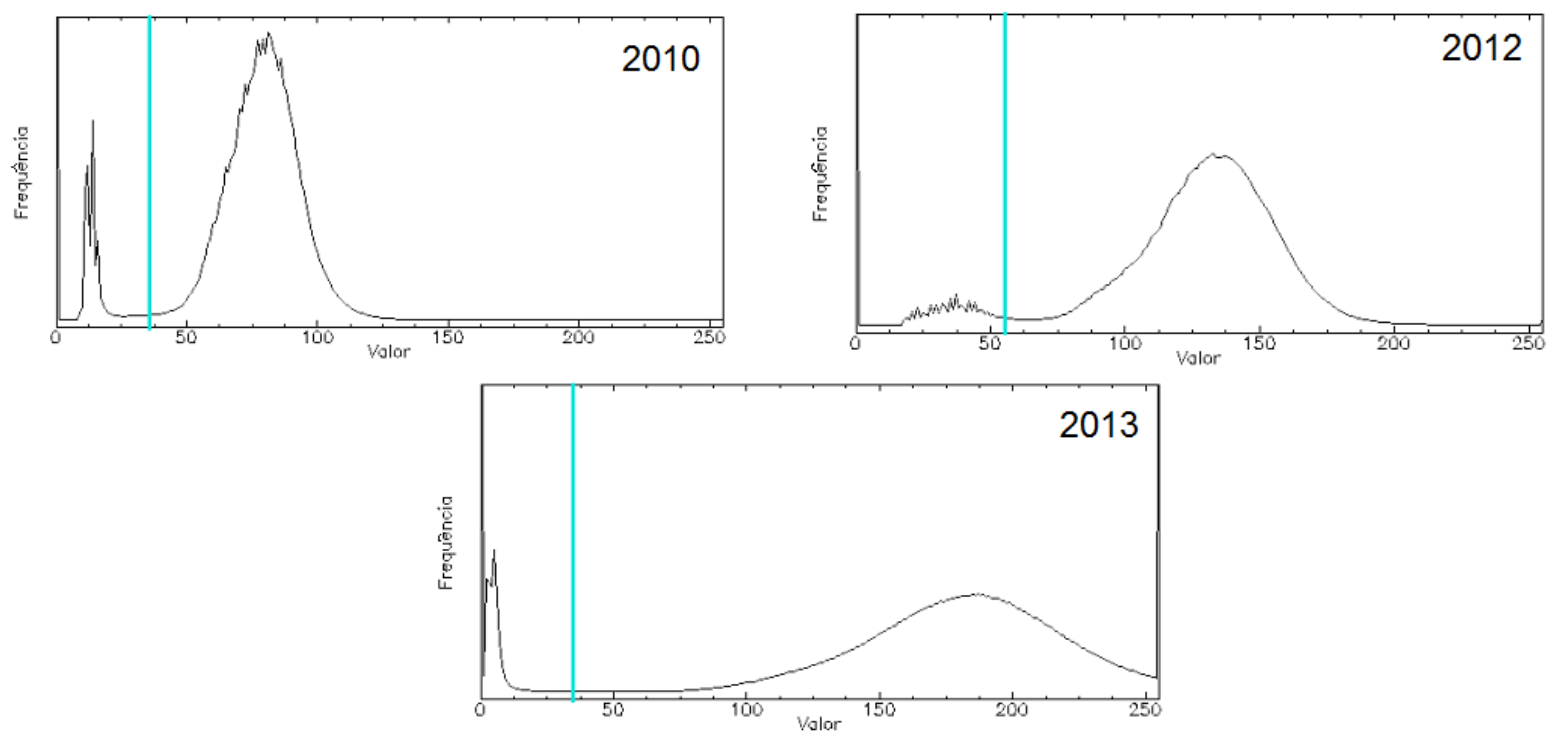

Figura 4. Histogramas dos mosaicos para os anos de 2010, 2012 e 2013, com valores de limiares de 35, 55 e 35 respectivamente (linha vertical em ciano).

\subsection{3. Álgebra de mapas e edição matricial}

Os resultados dos fatiamentos dos três anos foram combinados por meio de uma operação realizada pixel a pixel dentro da área delimitada como água na imagem base, gerando assim o mapa da redução da superfície de água livre. Desta forma, foi adotada a seguinte lógica: (i) se um pixel de água em 2010 foi classificado como sendo água em 2012 ele foi associado a classe permanente; (ii) se um 
pixel de água em 2010 foi classificado como não-água em 2012 ele foi associado classe de área inundada que foi perdida em 2012 e (iii) se um pixel classificado como sendo água em 2010 e não-água em 2012 e água em 2013 foi associado a classe recuperada. A Figura 6 apresenta um esquema desta operação.

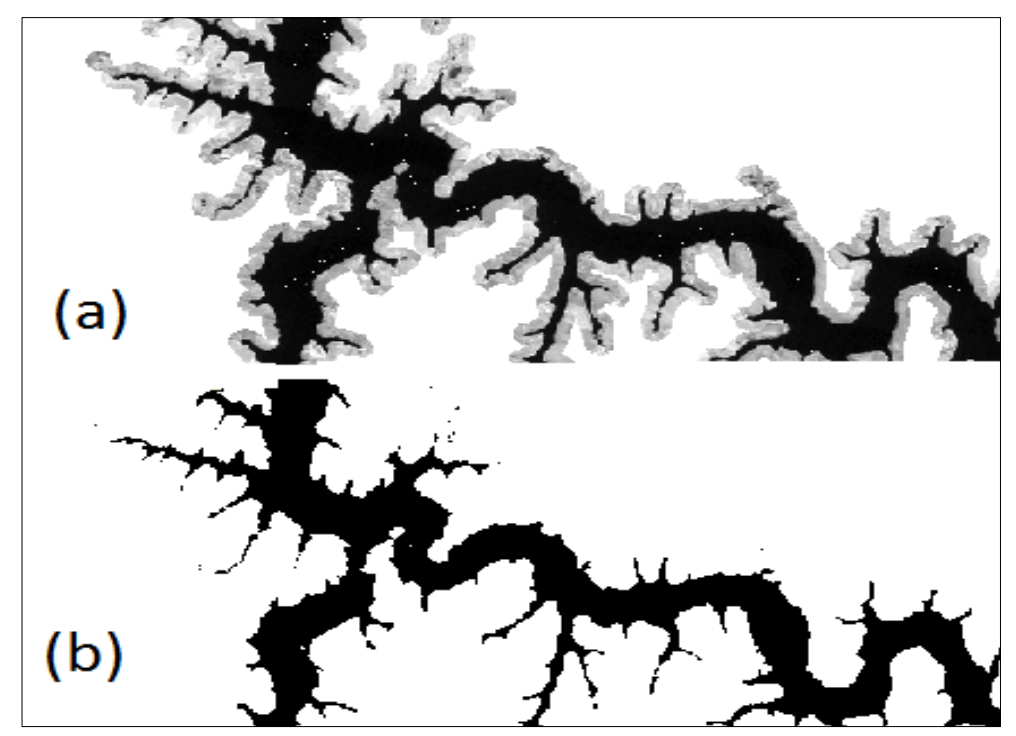

Figura 5. Fatiamento. Imagem a ser fatiada (a) e resultado do fatiamento (b) para o ano 2010.

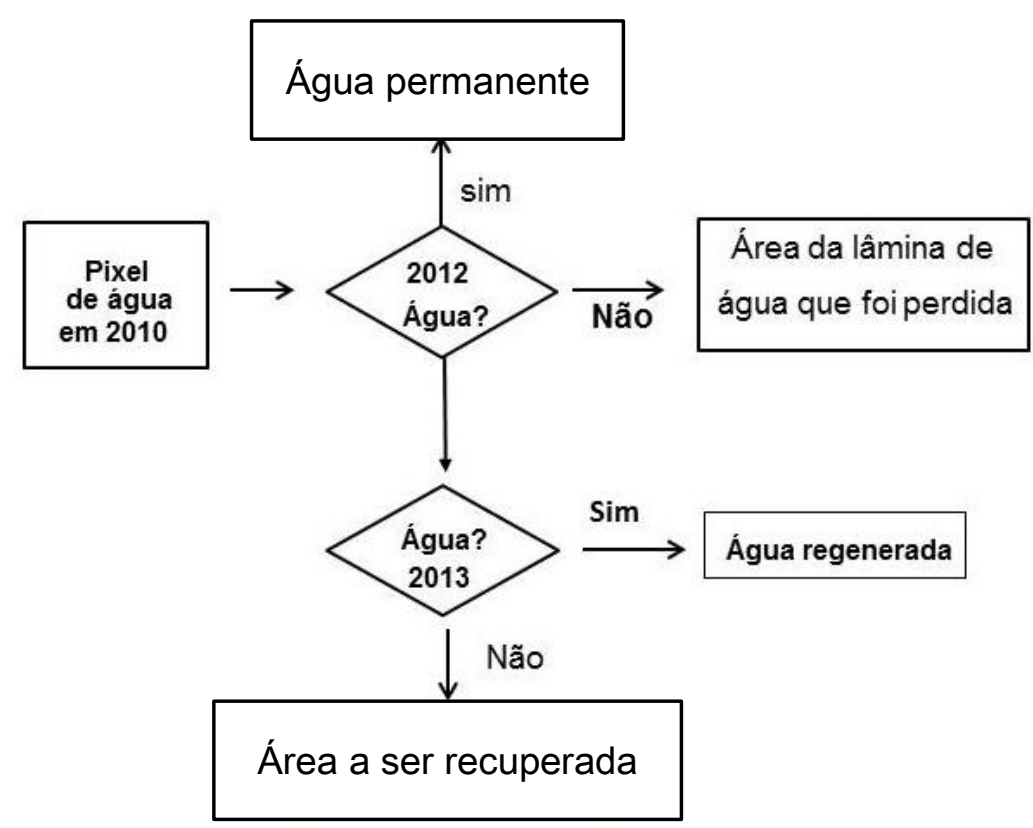

Figura 6. Fluxograma dos critérios de decisão adotados para classificar a área de estudo.

Qualquer que seja o procedimento de classificação, sempre haverá erros, que podem ser de inclusão ou de omissão (Camara et al., 1996). Os erros de inclusão são áreas que foram indevidamente classificadas como uma determinada classe, quando na verdade não era. Já os erros de omissão correspondem às áreas que não foram classificadas como uma dada classe de uso do solo, quando na verdade era. Para corrigir estes erros utiliza-se o procedimento de Edição Matricial (Moreira, 2005). 


\subsubsection{Cálculo das áreas}

O mapa resultante do processo de edição matricial foi cruzado com a base cadastral dos municípios brasileiros na escala 1:250.000 para a obtenção das áreas de superfícies de água permanente, recuperada e não recuperada por município. Primeiramente foi realizada uma interseção espacial, na qual foram selecionados apenas os municípios atravessados pela superfície de água do Lago no ano de referência (2010) (Figura 7). Na sequência foram calculadas as áreas de redução da superfície de água permanente para cada município. Os valores das áreas de cada classe foram utilizados para calcular as relações percentuais que constam na tabela de impacto/ recuperação (Tabela 4).

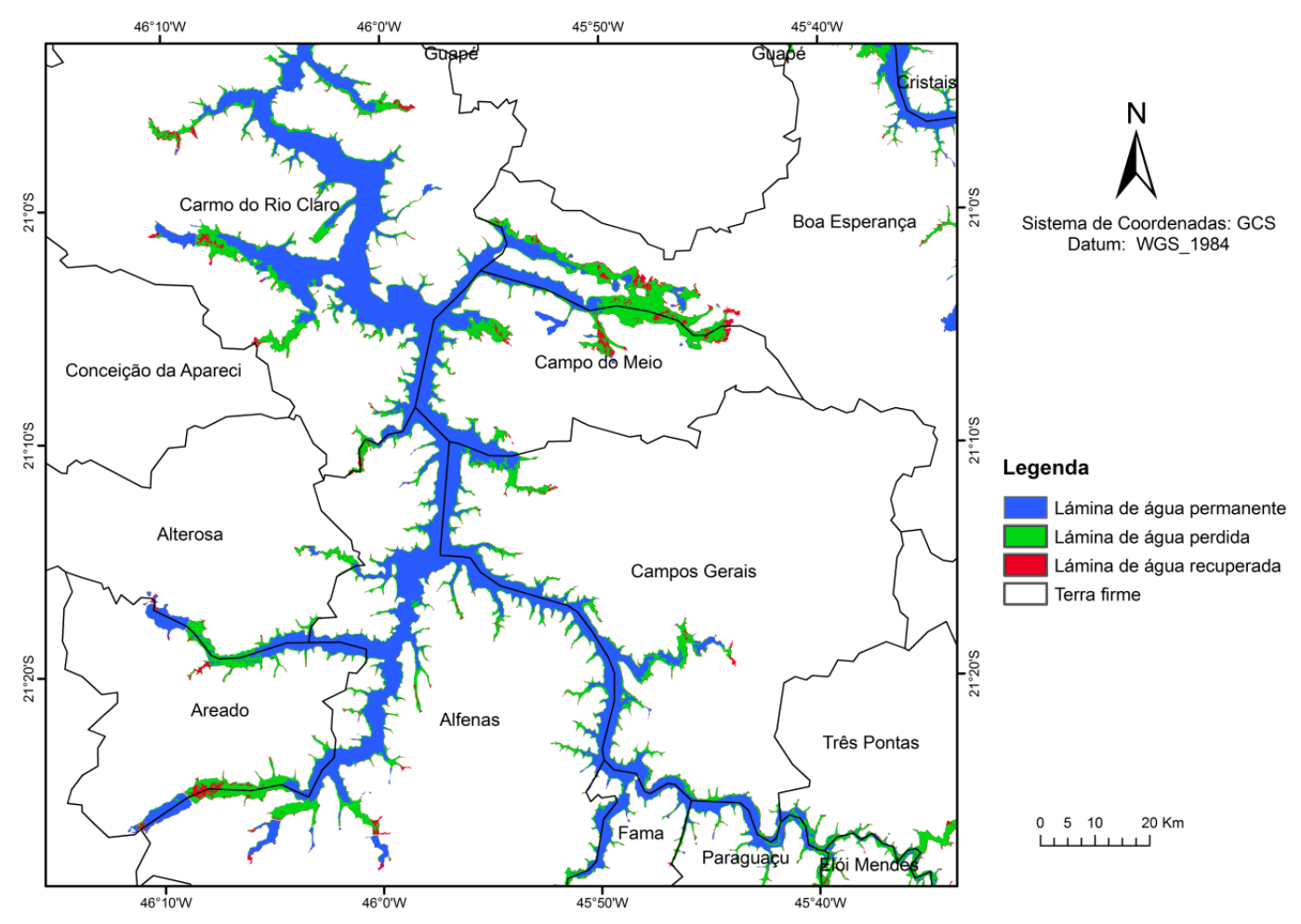

Figura 7. Municípios abrangidos pela superfície de água livre do Lago de Furnas.

\section{RESULTADOS E DISCUSSÃO}

\subsection{Correção dos erros de fatiamento}

Após o fatiamento observou que o mapa resultante apresentou erros tanto de inclusão quanto de omissão. Estes erros foram, então, corrigidos através da ferramenta Edição Matricial, disponíveis nos aplicativos de processamento de imagens. A Figura 8 mostra um recorte da área, seguido do mapa sem correção e do corrigido através da edição matricial.

Acredita-se que, devido à grande dimensão da área de estudo, os erros ocasionados por falhas na distinção entre a superfície de água e outras coberturas nos fatiamentos se deram, em grande parte, pela utilização de um único valor de limiar por ano para realizar esta separação. Estes erros foram detectados principalmente em relação ao ano de 2012 (durante o evento), o qual apresenta mais regiões em estados intermediários, entre o seco e o inundado, portanto é possível que a variabilidade espacial das respostas espectrais da superfície de água livre não tenha sido bem representada por um único valor de limiar neste ano. 


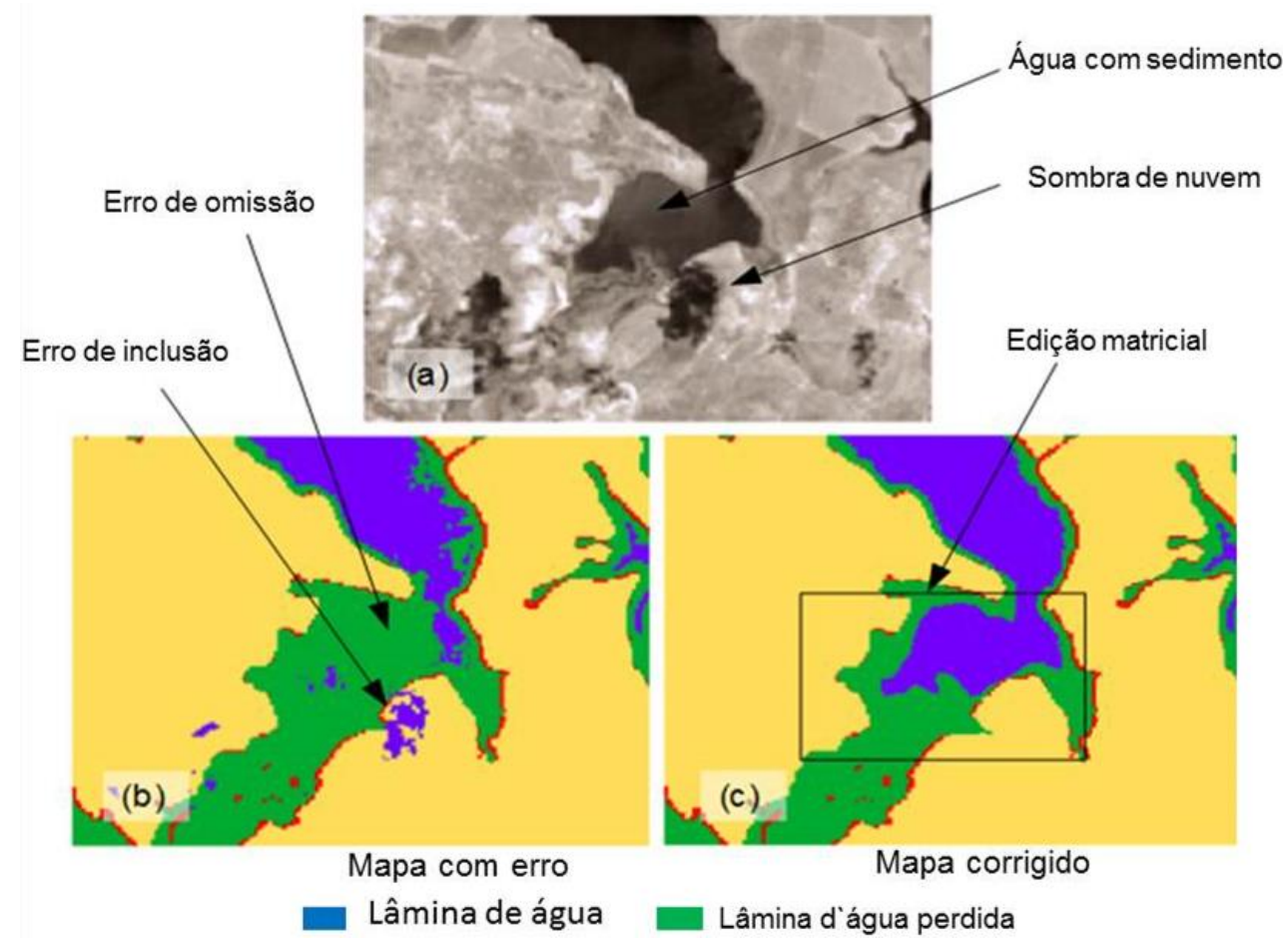

Figura 8. Recorte da área de estudo e os resultados do fatiamento para mostrar a correção dos erros de inclusão e omissão.

Na Figura 9 é mostrado o mapa com a espacialização da lâmina de água que prevaleceu no ano de 2012.

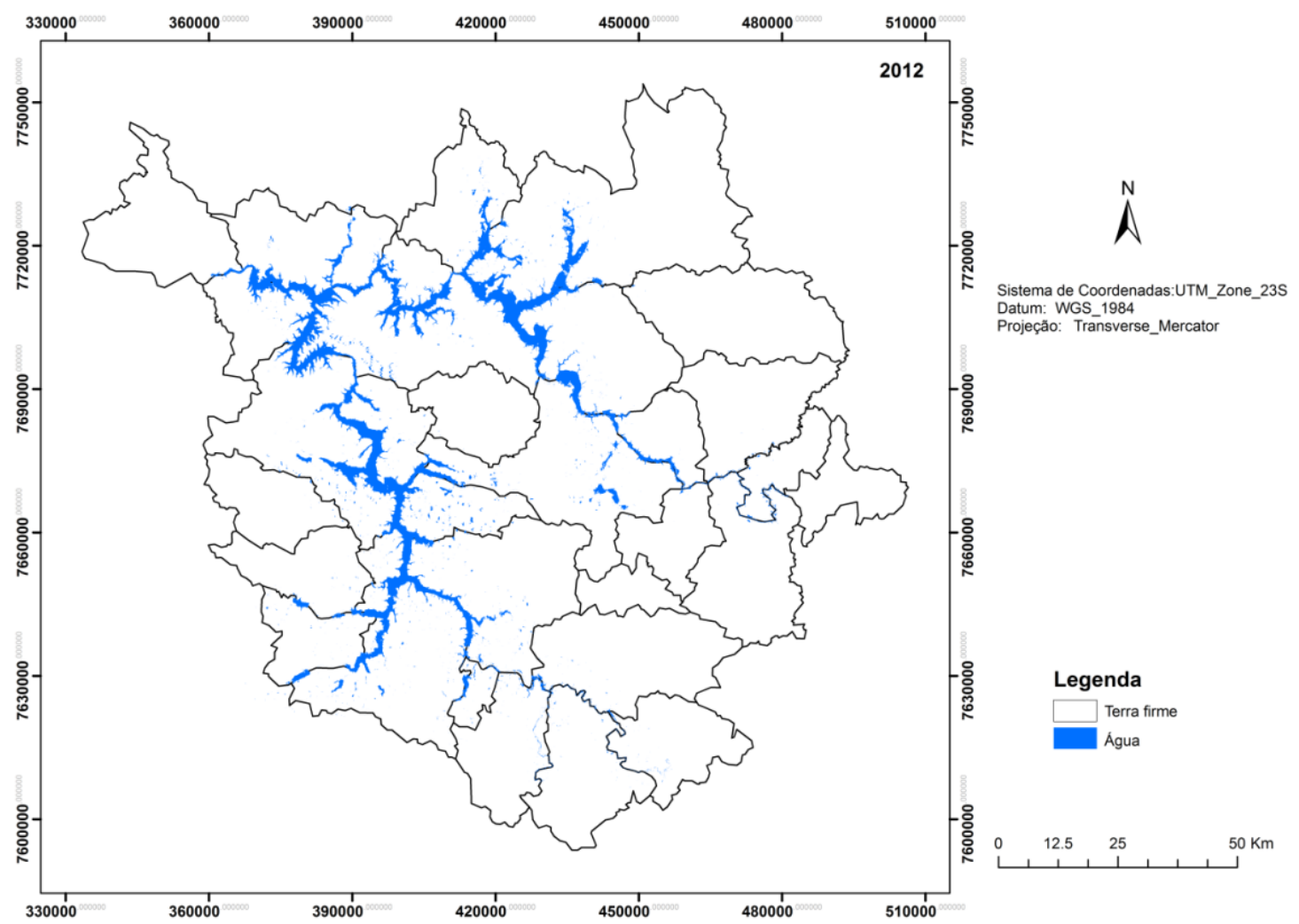

Figura 9. Área do Lago de Furnas coberta por água livre em 2012. 
Após realizar as devidas correções dos erros de fatiamento nos mapas dos três anos obteve-se, então, a espacialização da lâmina de água (permanente perdida e a recuperada). As informações contidas nos mapas foram sobrepostas e gerou-se um único mapa para mostrar a espacialização da lâmina de água que foi perdida no ano de 2012 e lâmina que foi recuperada no ano de 2013 (Figura 10).

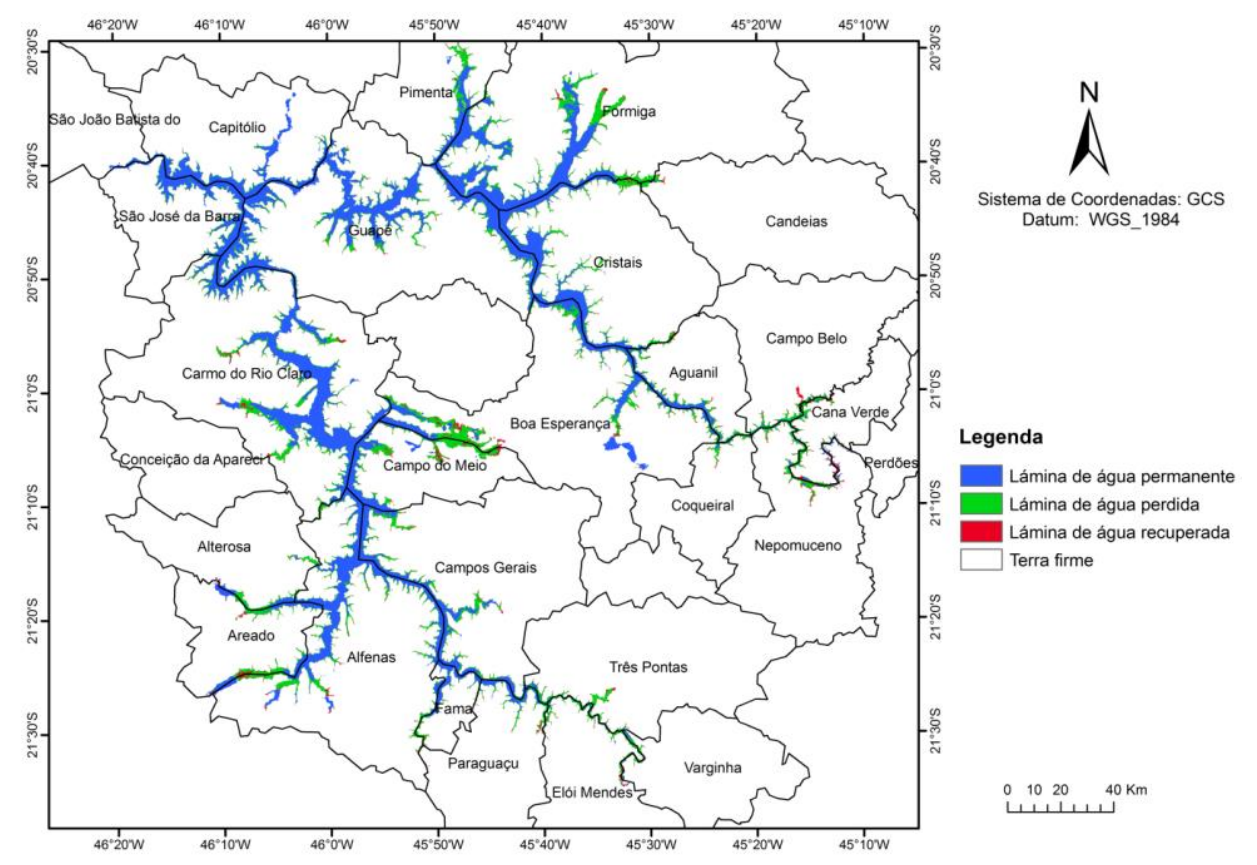

Figura 10. Redução da superfície de água livre do Lago Furnas.

Observando o mapa da Figura 10, nota-se que a situação foi muito grave em toda extensão do lago de Furnas, porém foi mais agravante próximo as nascentes. Detalhes podem ser visualizados na Figura 11, onde são mostradas ampliações de dois recortes, em duas regiões banhadas pelo lago de Furnas: um em Carmo do Rio Claro, localidade do Aterro de Santa Quitéria e outro em Campo Belo, distrito de Porto dos Mendes.

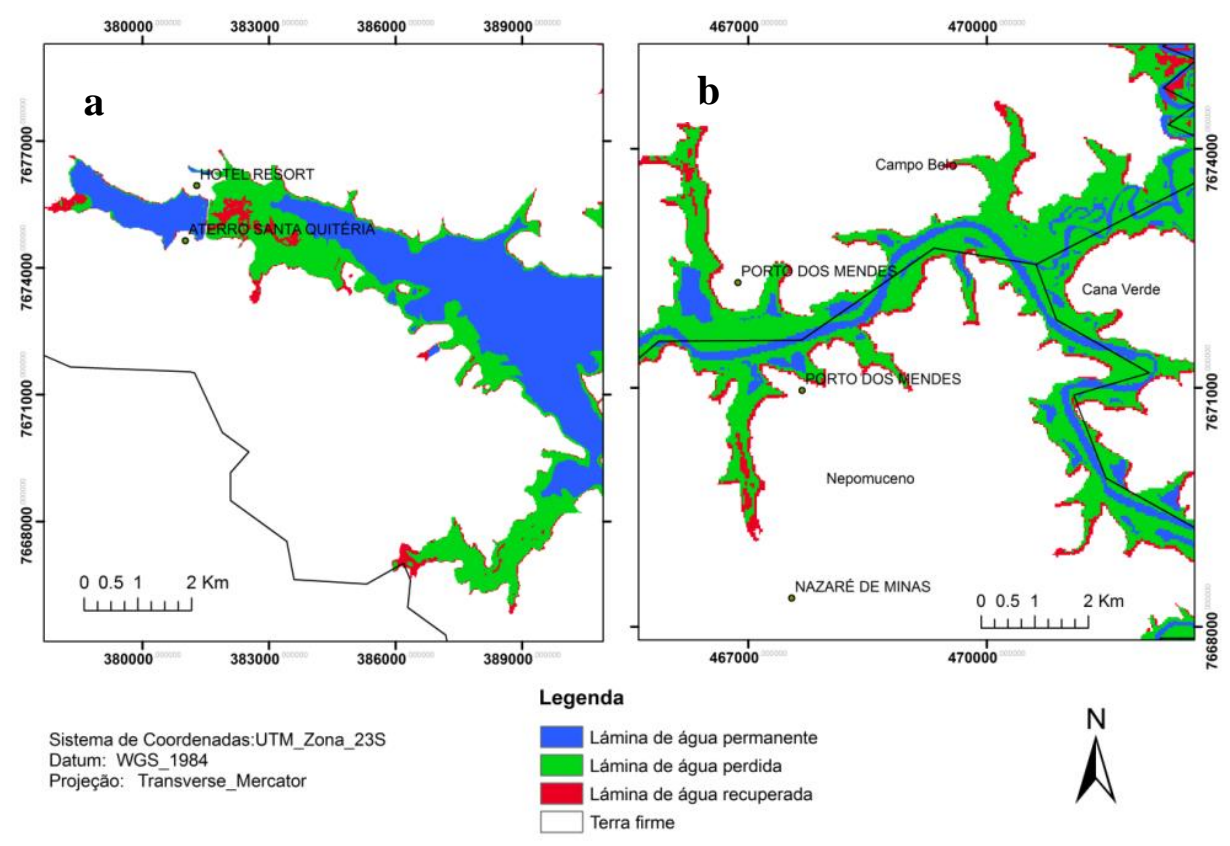

Figura 11. Ampliação do mapa da redução da superfície de água livre para alocalidadede Aterro de Santa Quitéria, em Carmo do Rio Claro (a) e distrito de Porto dos Mendes em Campo Belo- MG (b). 
Para realizar a avaliação quantitativa do mapa, o ideal seria que fosse realizada a comparação do resultado com medidas multi-temporais de réguas de medição de nível de água localizadas ao longo de todo o reservatório e com posições geográficas conhecidas. Todavia, este tipo de dado não foi obtido.

O mapa do ano de 2012 foi sobreposto com planos de informação contendo os municípios atravessados pelo lago e o cadastro de localidades do IBGE, permitindo assim identificar quais municípios foram mais afetados pela diminuição da lâmina de água.

A partir dos mapas e da malha municipal, foi possível quantificar o percentual da área do município coberto pelas águas do lago de Furnas em 2010, a porcentagem da superfície do município que estava seca em 2012 e a área recuperada em 2013 (Tabela 4).

Tabela 4. Porcentagem de área do município que estava coberta com água em 2010 (a), porcentagem de área perdida pelo afastamento da lâmina de água (b) e área recuperada de (b).

\begin{tabular}{|c|c|c|c|}
\hline Município & $\begin{array}{l}\text { Área do município } \\
\text { coberta com água em } \\
2010(\%)(a)\end{array}$ & $\begin{array}{l}\text { Porcentagem de (a) que estava } \\
\text { seca com a fuga da lâmina de } \\
\text { água }(\%)(b)\end{array}$ & $\begin{array}{l}\text { Porcentagem da área } \\
\text { recuperada de (b) (\%) }\end{array}$ \\
\hline Aguanil & 9,94 & 46,13 & 82,16 \\
\hline Alfenas & 14,43 & 32,80 & 81,20 \\
\hline Alterosa & 3,31 & 59,21 & 88,26 \\
\hline Areado & 10,23 & 49,72 & 79,65 \\
\hline Boa Esperança & 11,48 & 47,77 & 81,09 \\
\hline Campo Belo & 1,87 & 82,34 & 71,07 \\
\hline Campo do Meio & 17,35 & 17,35 & 81,69 \\
\hline Campos Gerais & 8,21 & 36,56 & 83,37 \\
\hline Cana Verde & 7,13 & 78,00 & 68,12 \\
\hline Candeias & 0,42 & 94,37 & 77,63 \\
\hline Capitólio & 9,23 & 16,44 & 82,88 \\
\hline Carmo do Rio Claro & 17,62 & 28,05 & 81,35 \\
\hline Coqueiral & 1,45 & 79,69 & 79,26 \\
\hline Cristais & 13,20 & 31,29 & 82,17 \\
\hline Elói Mendes & 2,59 & 82,41 & 81,36 \\
\hline Fama & 17,29 & 32,96 & 80,84 \\
\hline Formiga & 9,52 & 34,29 & 87,46 \\
\hline Guapé & 19,37 & 23,72 & 81,77 \\
\hline Nepomuceno & 2,95 & 76,90 & 67,92 \\
\hline Paraguaçu & 3,64 & 49,54 & 78,42 \\
\hline Pimenta & 6,99 & 46,60 & 88,50 \\
\hline São José da Barra & 14,59 & 17,24 & 82,45 \\
\hline Três Pontas & 1,84 & 78,02 & 83,90 \\
\hline Varginha & 1,12 & 76,93 & 81,17 \\
\hline TOTAL & & 36,14 & 81,55 \\
\hline
\end{tabular}


A partir dos dados contidos na Tabela 4 foram calculadas medidas de dispersão dos percentuais de área impactada e recuperada (Tabela 5). Os valores de média e desvio-padrão encontrados permitem inferir que a regeneração da superfície de água ocorreu mais uniformemente do que a sua secagem.

Os valores relativamente altos de regeneração encontrados podem ser explicados pelo bom regime de chuvas ocorrido no início do ano de 2013 nas cabeceiras dos rios que abastecem Furnas, todavia o reservatório só deve voltar ao seu nível normal em dois anos (Com chuvas de verão..., 2013; Mesmo com chuva..., 2013).

Tabela 5. Medidas de dispersão dos percentuais de área impactada e recuperada.

\begin{tabular}{lcc}
\hline Medida de dispersão & $\begin{array}{c}\text { Área impactada/área de referência } \\
(\%)\end{array}$ & $\begin{array}{c}\text { Área recuperada/área impactada } \\
(\%)\end{array}$ \\
\hline Média & 52,17 & 80,57 \\
Desvio Padrão & 23,01 & 5,12 \\
\hline
\end{tabular}

\section{CONCLUSÃO}

De acordo com os resultados do trabalho chegou-se às seguintes conclusões:

As imagens dos sensores LISS3/Resourcesat e do OLI/Landsat 8 permitiram avaliar espacialmente o impacto e a recuperação das áreas no entorno do lago de Furnas.

Foi possível quantificar por município a área que foi atingida pela diminuição do nível de água.

A metodologia utilizada é de fácil utilização e pode ser empregada no monitoramento das águas do lago e de outras represas.

Como recomendação para futuros trabalhos, é sugerido avaliar o mapa com dados coletados a campo, tanto de medidas de réguas de nível d'água, como medidas de precipitação.

\section{AGRADECIMENTOS}

O segundo autor agradece ao Banco Mundial pelo financiamento dos estudos de nível de mestrado. Ao Ministério da Ciência e Tecnologia de Moçambique, gestora dos fundos da Bolsa e à Universidade Estadual de Feira de Santana (UEFS) pelo ingresso e frequência no programa de mestrado (PPGM).

\section{REFERÊNCIAS}

BUTZKE, I. C. Ocupação de áreas inundáveis em Blumenau (SC). 1995. $245 f$. Dissertação (Mestrado em Geografia) - Universidade Estadual Paulista, Rio Claro, 1995.

CÂMARA G.; SOUZA, R. C. M.; FREITAS, U. M.; GARRIDO, J. Spring: integrating remote sensing and GIS by object oriented data modelling. Computers \& Graphics, v. 20, n. 3, p. 395-403, 1996. http://dx.doi.org/10.1016/0097-8493(96)00008-8

CAMPOS, J. C. de; SILVA, A. C. Avaliação do desmatamento na região de Alfenas no período de 1964 a 2001 através do sensoriamento remoto. Revista Universidade de Alfenas, Alfenas, v. 4, p. 111-114, 1998. 
CENTRO NACIONAL DE MONITORAMENTO E ALERTAS DE DESASTRES NATURAIS - CEMADEN. Localização do Lago de Furnas na bacia do Rio Grande e detalhamento do Lago de Furnas, com destaque para as usinas hidrelétricas e contexto municipal. Elaborado por Claudia de Albuquerque Linhares. Cachoeira Paulista, 2014.

CHANDER, G. Overview of the Resourcesat-1 (IRS-P6). Disponível em: $<$ http://calval.cr.usgs.gov/documents/IRSP6.pdf>. Acesso em: 09 jul. 2013.

COM chuvas de verão, Lago de Furnas começa a recuperar seu nível. G1, Sul de Minas, jan. 2013. Disponível em: http://g1.globo.com/mg/sul-de-minas/noticia/2013/01/comchuvas-de-verao-lago-de-furnas-comeca-recuperar-seu-nivel.html. Acesso em: 16 ago. 2013.

FERREIRA, M. F. M.; OLIVEIRA, R. L. de S.; GARÓFALO, D. F. T. Delimitação e caracterização das unidades de paisagem da região de Alfenas, sul de Minas Gerais, a partir de dados do radar SRTM e imagem orbital ETM+ Landsat 7. In: SIMPÓSIO NACIONAL DE GEOMORFOLOGIA, 8., ENCONTRO LATINO AMERICANO DE GEOMORFOlOGIA, 2., 2008, Belo Horizonte-MG. Anais... Belo Horizonte: IGCUFMG, 2008.

INSTITUTO BRASILEIRO DE GEOGRAFIA E ESTATISTICA - IBGE. Web site. 2010. Disponível em: <www.ibge.gov.br>. Acesso em: 15 ago. 2013.

INSTITUTO DE PESQUISAS TECNOLÓGICAS -IPT. Diagnóstico da situação dos recursos hídricos na Bacia Hidrográfica do Rio Grande (BHRG) - SP/MG (Relatório Síntese - R3). Relatório Técnico no 96.581-205 - i/ii. [S.1.], mar. 2008. p. 52.

INSTITUTO NACIONAL DE PESQUISAS ESPACIAIS - INPE. Características técnicas do sensor LISS-3. Disponível em: http://www.dgi.inpe.br/CDSR/ir-p6.html. Acesso em: 09 jul. 2013.

JENSEN, J. R. Sensoriamento remoto do ambiente: uma perspectiva em recursos terrestres. [S.1.]: Parêntese, 2009.

JOHNSON, D. M. A comparison of coincident Landsat-5 TM and Resourcesat-1 AWiFS Imagery for classifying croplands. Photogrammetric Engineering \& Remote Sensing, v. 74, n. 11, p. 1413-1423, 2008.

http://dx.doi.org/10.14358/PERS.74.11.1413

MESMO com chuva, Lago de Furnas só deve voltar ao normal em 2 anos. G1, Sul de Minas, fev. 2013. Disponível em: http:/g1.globo.com/mg/sul-de-minas/noticia/ 2013/02/mesmo-com-chuva-lago-de-furnas-so-deve-voltar-ao-normal-em-2-anos.html. Acesso em: 16 ago. 2013.

MOREIRA, M. Fundamentos do sensoriamento remoto e metodologias de aplicação. 3. ed. Viçosa: UFV, 2005. p. 307.

MOTA, S. Preservação e conservação de recursos hídricos. 2. ed. São Paulo: ABES, 1995.

NATIONAL REMOTE SENSING AGENCY - NRSA. RESOURCESAT - 1 (IRS - P6): DATA USER'S HANDBOOK. IRS-P6/NRSA/NDC/HB-10/03, India. [S.1.], Oct. 2003. p. 142. 
PINTO-COELHO, R.; GIANI, A.; VON SPERLING, E. (eds.). Ecology and human impact on lakes and reservoirs in Minas Gerais with special reference to future development and management strategies. Belo Horizonte: SEGRAC, 1994. p. 193.

SANTOS, C.; MARTINS, M.; MARTINS, B. Uso da terra nas margens do reservatório de Furnas, sul de Minas Gerais, Brasil. SIMPÓSIO BRASILEIRO DE SENSORIAMENTO REMOTO - SBSR, 15., 30 abr. a 05 maio 2011, Curitiba. Anais... São José dos Campos: INPE, 2011. p. 6246.

SILVA, Samantha. Lago de Furnas enfrenta pior seca em 10 anos, diz associação em MG. G1, Sul de Minas, nov. 2012. Disponivel em: http://g1.globo.com/mg/sul-deminas/noticia/2012/11/lago-de-furnas-enfrenta-pior-seca-em-10-anos-diz-alago.html. Acesso em: 05 jul. 2013.

TUNDISI, J. G. Reservatórios como sistemas complexos: teoria, aplicações e perspectivas para usos múltiplos. In: HENRY, R. (Ed.). Ecologia de reservatórios: estrutura, função e aspectos sociais. Botucatu: FAPESP; FUNDIBIO, 1999. p. 22-38.

UNITED STATES GEOLOGICAL SURVEY - USGS. Landsat Data Continuity Mission (Ldcm), Level 0 Reformatted (LOr) Data Format Control Book (Dfcb). LDCMDFCB-002 Version 9.0. Sioux Falls: EROS, 2012. p. 97.

UNITED STATES GEOLOGICAL SURVEY - USGS. Landsat Data Continuity Mission (Ldcm), Level 1 (L1) Data Format Control Book (DFCB). LDCM-DFCB-004 Version 6.0. Sioux Falls: EROS, 2012.p. 81. 